\title{
Warfarin anticoagulation in hemodialysis patients with atrial fibrillation: comparison of nephrologist-led and anticoagulation clinic-led management
}

\author{
Hamad Bahbahani ${ }^{1 * \dagger}$, Ahmed AlTurki ${ }^{2 \dagger}$, Ahmed Dawas ${ }^{3}$ and Mark L. Lipman ${ }^{4}$
}

\begin{abstract}
Background: There is conflicting evidence of benefit versus harm for warfarin anticoagulation in hemodialysis patients with atrial fibrillation. This equipoise may be explained by suboptimal Time in Therapeutic Range (TTR), which correlates well with thromboembolic and bleeding complications. This study aimed to compare nephrologist-led management of warfarin therapy versus that led by specialized anticoagulation clinic.

Methods: In a retrospective cohort of chronic hemodialysis patients from two institutions (Institution A: Nephrologist-led warfarin management, Institution B: Anticoagulation clinic-led warfarin management), we identified patients with atrial fibrillation who were receiving warfarin for thromboembolic prophylaxis. Mean TTRs, proportion of patients achieving $T T R \geq 60 \%$, and frequency of INR testing were compared using a logistic regression model.

Results: In Institution A, $16.7 \%$ of hemodialysis patients had atrial fibrillation, of whom $36.8 \%$ were on warfarin. In Institution $B, 18 \%$ of hemodialysis patients had atrial fibrillation, and $55.5 \%$ were on warfarin. The mean TTR was $61.8 \%$ (SD 14.5) in Institution A, and 60.5\% (SD 15.8) in Institution B ( $p$-value 0.95). However, the proportion of patients achieving $T \mathrm{TR} \geq 60 \%$ was $65 \%$ versus $43.3 \%$ (Adjusted OR 2.22, $\mathrm{Cl} 0.65-7.63$ ) and mean frequency of INR testing was every 6 days versus every 13.9 days in Institutions A and B respectively.

Conclusions: There was no statistical difference in mean TTR between nephrologist-led management of warfarin and that of clinic-led management. However, the former achieved a trend toward a higher proportion of patients with optimal TTR. This improved therapeutic results was associated with more frequent INR monitoring.
\end{abstract}

Keywords: Hemodialysis, Atrial fibrillation, Warfarin, Time in therapeutic range, International normalized ratio (INR)

\section{Background}

Warfarin is a mainstay therapy for reducing stroke risk in atrial fibrillation [1-4]. The use of a target international normalized ratio (INR) between 2 and 3 decreases thromboembolic risks without a significant increase in the risk of major bleeding $[1,5,6]$. The risk of thromboembolic events is even higher in patients with advanced chronic kidney disease, when compared to the general population leading to a higher morbidity and mortality in this

\footnotetext{
*Correspondence: dr.hamad_bahbahani@hotmail.com

${ }^{\dagger}$ Equal contributors

${ }^{1}$ Division of Nephrology, Department of Medicine, McGill University Health

Centre, Montreal, Canada

Full list of author information is available at the end of the article
}

population $[4,7,8]$. There is conflicting evidence of benefit versus harm for anticoagulation in hemodialysis patients. Several studies have demonstrated decreased mortality and a decreased risk of stroke with warfarin [7-9]. In contrast, other studies reported an increased risk of bleeding, without a significant impact on ischemic stroke risk or mortality [10], and even an increased risk of stroke, whether ischemic or hemorrhagic [11, 12]. This equipoise is reflected in the guidelines published by various national and international societies, with some advocating a prominent role for warfarin in hemodialysis patients with atrial fibrillation [3], while others adopting a contrary position, in which they advise against the use of warfarin for primary thromboembolic prophylaxis in hemodialysis patients with 
atrial fibrillation $[4,13]$. The Kidney Disease: Improving Global Outcomes, guidelines now state that routine anticoagulation of stage 5 chronic kidney disease patients with atrial fibrillation for primary prevention of stroke is not indicated [13].

Time in therapeutic range (TTR), as measured by the Rosendaal method [14], was found to correlate well with bleeding and thromboembolic complications, and a TTR of $<60 \%$ has been associated with increased mortality, major bleeding and systemic embolism [15]. Hemodialysis patients on warfarin were found to have lower TTR compared to the general population, though data is limited. Two retrospective studies reported TTRs of 49.2\% [16] and $45.1 \%$ [17]. In a prospective study, Genovesi et al. demonstrated an overall median TTR of only $54 \%$ in hemodialysis patients on warfarin [18]. This study also showed that an improved TTR was correlated with lower risk of hemorrhage. Therefore, it is possible that the advantages of warfarin are not demonstrated in hemodialysis patients, in part, due to the suboptimal TTRs.

Anticoagulation management directed by specialized anticoagulation clinics has been found to reduce thromboembolic and bleeding complications, as well as optimize TTR in atrial fibrillation patients [19]. Furthermore, a recent systematic review demonstrated superior anticoagulation management by pharmacists compared to usual medical care (i.e anticoagulation management directed by the primary care provider) [20]. However, data based on TTR does not exist for the hemodialysis population. This study compared nephrologist-led management of warfarin therapy in terms of achieved TTR and frequency of INR testing, to specialized thrombosis clinic-led management in chronic hemodialysis patients.

\section{Methods}

\section{Study design and settings}

This is a retrospective cohort study of chronic hemodialysis patients with atrial fibrillation receiving warfarin for the prevention of thromboembolic complications of atrial fibrillation in two university teaching hospitals; the McGill University Health Centre (MUHC) and the Jewish General Hospital (JGH), both located in Montreal, Canada. Between January 2015 and November 2016, patients receiving hemodialysis at the above institutions were screened for eligibility. At the MUHC, warfarin-based anticoagulation is managed by nephrologists, whereas at the JGH it is managed through an anticoagulation clinic led by hematologists. The study was approved by the Medical/Biomedical Research Ethics Committee of the West-Central Montreal Island Health Board.

\section{Study population and data collection}

Patients were identified using the following inclusion criteria: a minimum age of 18 years, on maintenance hemodialysis for end-stage renal disease, a documented history of atrial fibrillation or atrial flutter, and on warfarin for a minimum of 3 months. Patients who were on hemodialysis during part of the study period but either died, received a renal transplant, or were transferred to another centre for hemodialysis were included in the study. Patients were included if their total duration of nonhospitalized INR testing while on warfarin was at least 140 days, to ensure sufficient INR data for TTR analysis.

INR values on warfarin were collected retrospectively for up to 1 year starting from the last encounter with the patient during the study period. INR values during hospital admissions lasting more than 2 days were excluded as were any INRs obtained within the first week post discharge. The following additional data were collected from dialysis charts and/or electronic medical records: demographics (age and gender), CHADS2 score, total duration on hemodialysis, relevant comorbidities (congestive heart failure, coronary artery disease, hypertension, type 2 diabetes mellitus, cerebrovascular accidents, valvular atrial fibrillation), medication use (antiplatelet agents, NSAIDs, total duration of outpatient antibiotic use), and total number of days of hospitalization during the study period.

\section{Study end points}

The end points of the study were; 1) the mean TTR, based on the Rosendaal method, 2) the proportion of patients achieving TTR $\geq 60 \%$, based on the Rosendaal method, 3) mean frequency of INR testing.

\section{Statistical analyses}

The study cohort was stratified into two groups, Nephrologist-led management (Institution A) and Anticoagulation clinic-led management (Institution B). Continuous variables were expressed as mean \pm standard deviation (SD) using paired t-test analysis, whereas, the Chi-square and Fisher exact tests were used to compare binary variables. TTR results from both institutions were fitted in a regression model using PROC GLM, and a logistic model using PROC LOGISTIC was used in the analysis of proportion of patients achieving TTR $\geq 60 \%$. Adjustments for the following variables were performed when calculating $p$ values and Odds Ratio (OR): hemodialysis vintage, total duration of hospitalization, and total number of days of outpatient antibiotic use. All statistical analyses were performed using SAS version 9.4.

\section{Cost analysis}

To evaluate cost effectiveness of the two strategies, we utilized the laboratory cost of INR assay ( 0.50 Canadian dollars per test) and the per test professional fee allocated for warfarin management to anti-coagulation clinic physician (12.50 Canadian dollars) applicable for the 
Province of Quebec, Canada. The nephrologist is not eligible for the professional fee.

\section{Results}

For the period starting from January 1st, 2015 and ending on November 26th, 2016, we identified 341 patients in Institution A and 300 patients in Institution B who were undergoing hemodialysis for at least 3 months. In Institution A, 57 patients $(16.7 \%)$ had documented history of atrial fibrillation, of whom 21 (36.8\%) were on warfarin at the end of the study period. In Institution B, 54 patients (18\%) had history of atrial fibrillation, and 30 (55.5\%) were on warfarin. Following the application of the inclusion criteria, the INR data of 20 patients in Institution A and 30 patients in Institution B were included in the final TTR analysis. A flow diagram of the study is illustrated in (Fig. 1).

\section{Patient characteristics}

The baseline characteristics of patients included in the TTR analysis are shown in (Table 1). Mean age was 75.6 and 79.3 years in Institution A and Institution B, respectively, of which $60 \%$ were male in both institutions. The distribution of medical co-morbidities associated with increased stroke risk (such as previous CVA, type 2 DM, hypertension, congestive heart failure, and valvular atrial fibrillation), as well as CHADS2 scores were similar in both institutions. Hemodialysis patient vintage was also comparable (Institution A: mean $42.6 \pm 39.6$ months, Institution B: $50.8 \pm 52.7$ months). Despite the similar number of hospitalization events in patients from both institutions, the patients in Institution A had a shorter duration of hospitalization (mean 10.9 \pm 15.6 days) compared to those in Institution B (mean $20 \pm 36.4$ days). However, this difference was not statistically significant. Moreover, the

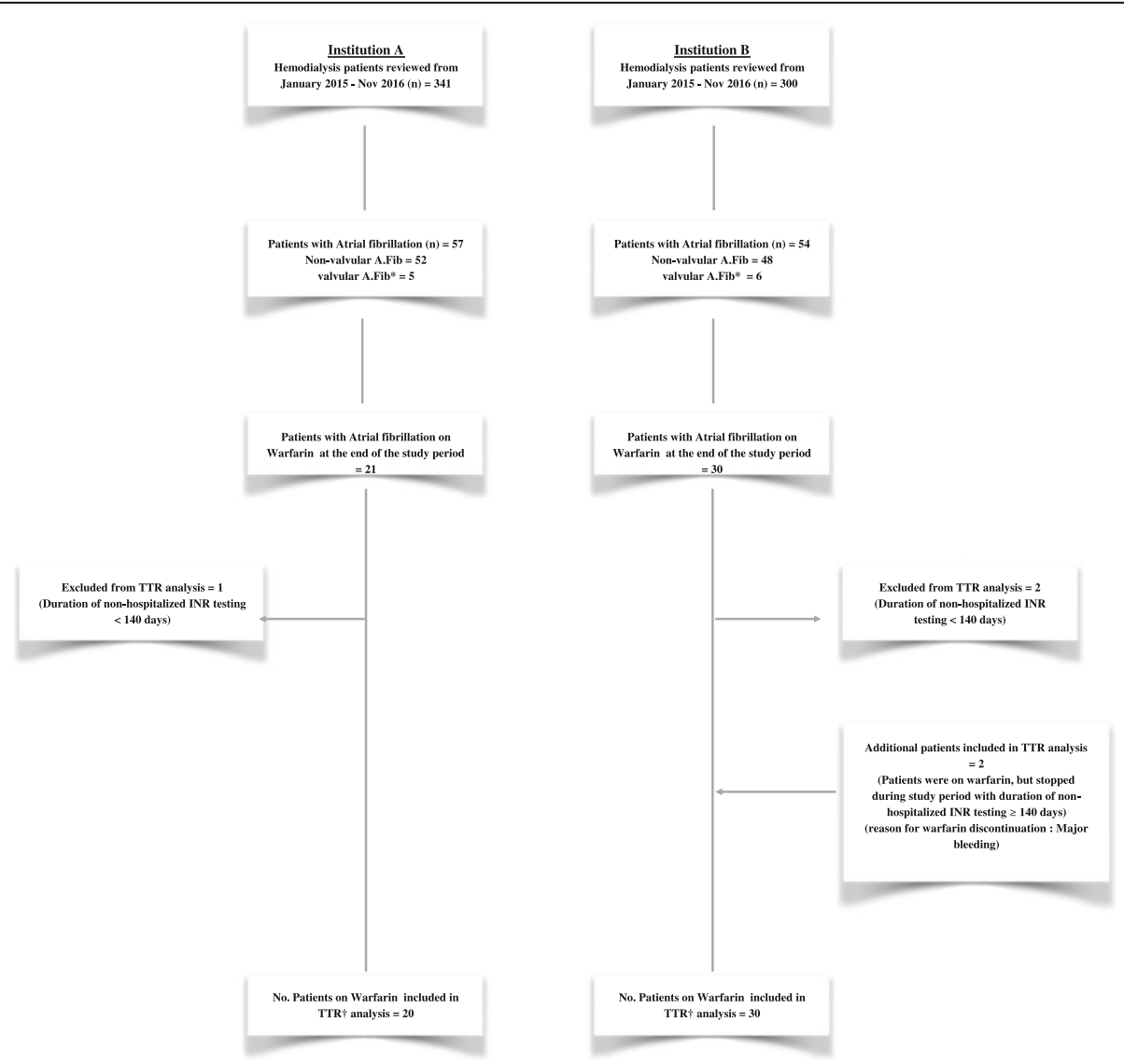

Fig. 1 A diagram of the flow of the study. In Institution A: 57 out of 341 patients on chronic hemodialysis had a documented history of atrial fibrillation. Of whom, 52 patients had non-valvular Atrial fibrillation, and 5 had valvular atrial fibrillation. 21 patients were still on warfarin at their last encounter during the study period, in whom, 1 patient was excluded because duration of outpatient INR testing was $<140$ days. 20 patients were included in the final TTR analysis. In Institution B: 54 out of 300 patients on chronic hemodialysis had a documented history of atrial fibrillation. Of whom, 48 patients had non-valvular Atrial fibrillation, and 6 had valvular atrial fibrillation. 30 patients were still on warfarin at their last encounter during the study period, in whom, 2 patient were excluded because duration of outpatient INR testing was $<140$ days. 2 patients were added to the final TTR analysis, because they were on warfarin, but stopped during study period with duration of non-hospitalized INR testing $\geq 140$ day. 30 patients were included in the final TTR analysis. *valvular atrial fibrillation: atrial fibrillation in patients with rheumatic mitral disease, mitral stenosis or prosthetic heart valves; †TR: Time in Therapeutic Range 
Table 1 Baseline characteristics of hemodialysis patients on warfarin

\begin{tabular}{|c|c|c|c|}
\hline & $\begin{array}{l}\text { Institution A } \\
n=20\end{array}$ & $\begin{array}{l}\text { Institution B } \\
n=30\end{array}$ & P-value \\
\hline Age, yrs & 75.6 & 79.3 & 0.25 \\
\hline Male, $n(\%)$ & $12(60)$ & $18(60)$ & 1 \\
\hline \multicolumn{4}{|l|}{ Comorbidities, $n$ (\%): } \\
\hline $\mathrm{CHF}$ & $11(55)$ & $17(56.7)$ & 0.91 \\
\hline CAD & $11(55)$ & $16(53.3)$ & 0.91 \\
\hline DM (Type 2) & $9(45)$ & $17(56.7)$ & 0.42 \\
\hline CVA & $8(40)$ & $8(26.7)$ & 0.32 \\
\hline HTN & $16(80)$ & $27(90)$ & 0.42 \\
\hline Valvular A.Fib & $5(25)$ & $6(20)$ & 0.74 \\
\hline HD Vintage, months (mean \pm SD) & $42.6 \pm 39.6$ & $50.8 \pm 52.7$ & 0.54 \\
\hline CHADS2 score (mean) & 3.6 & 3.4 & 0.65 \\
\hline No. Hositalization events (mean) & 0.8 & 1.13 & 0.27 \\
\hline $\begin{array}{l}\text { Total duration of Hospitalization, } \\
\text { days (mean } \pm \text { SD) }\end{array}$ & $10.9 \pm 15.6$ & $20 \pm 36.4$ & 0.23 \\
\hline $\begin{array}{l}\text { Total duration of outpatient } \\
\text { Antibiotic use, days (mean } \pm \text { SD) }\end{array}$ & $12.5 \pm 26.0$ & $27.1 \pm 66.7$ & 0.28 \\
\hline
\end{tabular}

CHF congestive heart failure, CAD coronary artery disease, HTN hypertension, DM Diabetes Mellitus, Valvular A.Fib atrial fibrillation with rheumatic mitral disease, mitral stenosis or prosthetic heart valves, $H D$ hemodialysis

duration of outpatient antibiotic use was shorter in the patients of Institution $\mathrm{A}$ in comparison to those of Institution B (mean $12.5 \pm 26.0$ vs $27.1 \pm 66.7$ days, respectively), but the difference was not statistically significant.

\section{TTR analysis}

The mean TTR, based on Rosendaal method, was $61.8 \%$ (SD 14.5) at Institution A, and 60.5\% (SD 15.8) at Institution $\mathrm{B}$ (unadjusted $p$-value 0.76 , adjusted $p$ value 0.95 ) (Table 2). The mean frequency of INR testing was every 6 days in Institution A versus every 13.9 days in Institution B.

Analysis of patients achieving the target TTR $\geq 60 \%$, based on Rosendaal method, is illustrated in (Table 3) and (Fig. 2). At Institution A, 65\% of hemodialysis patients taking warfarin achieved TTR $\geq 60 \%$, whereas only $43.3 \%$ of patients at Institution B achieved that target level of TTR. The crude odds ratio of patients achieving TTR $\geq 60 \%$ at Institution A was 2.43 compared to Institution B. Even after adjustment for hemodialysis vintage, total duration of hospitalization, and total duration of outpatient antibiotic use, the odds ratio of patients achieving TTR $\geq 60 \%$ remained at 2.22 (95\% CI $0.65-7.63)$.

Table 2 Mean TTR measures between Institution (A) and (B)

\begin{tabular}{|c|c|c|c|c|}
\hline & $\begin{array}{l}\text { Institution A } \\
(n=20)\end{array}$ & $\begin{array}{l}\text { Institution B } \\
(n=30)\end{array}$ & Difference & $\begin{array}{l}\text { Adjusted }^{\mathrm{a}} \\
P \text { - value }\end{array}$ \\
\hline $\begin{array}{l}\text { Rosendaal method, } \\
\%\end{array}$ & 61.8 & 60.5 & 1.3 & 0.95 \\
\hline
\end{tabular}

\section{Cost analysis}

The average annual number of INR tests was 60 in Institution A (nephrologist-led management) and 26 in Institution $\mathrm{B}$ (anti-coagulation clinic-led management). Therefore, at a total per test cost of $0.50 \$ C A N$, the average annual cost of INR testing per patient in Institution $\mathrm{A}$ is approximately 30.00 \$CAD, whereas, at a total per test cost of $12.50 \$ C A N$, the average annual cost of INR testing per patient in Institution B is 338.00 \$CAN. Therefore, there is significant overall cost savings associated with nephrologistled warfarin management despite more frequent INR testing. It is important to note that this analysis is based on laboratory and professional fees specific to the Province of Quebec, Canada, which vary somewhat among Canadian provinces and more so across other countries.

\section{Discussion}

Our study demonstrates a nearly equal mean TTR among chronic hemodialysis patients receiving warfarin, whether managed by specialized anticoagulation clinic or by nephrologists. In addition, both management modalities achieved mean TTRs that were superior to previously published data in hemodialysis patients, and comparable to those reported in general population. Interestingly, nephrologist-led warfarin management achieved more patients at the target TTR $\geq 60 \%$ than that achieved by anticoagulation clinic, with an odds ratio greater than 2 . This outcome correlated with the higher frequency of INR testing that was observed with nephrologist-led management. 
Table 3 Odds ratio (OR) of patients with optimal TTR

\begin{tabular}{|c|c|c|c|c|c|}
\hline & $\begin{array}{l}\text { Institution A } \\
(n=20)\end{array}$ & $\begin{array}{l}\text { Institution B } \\
(n=30)\end{array}$ & $\begin{array}{l}\text { Crude Odds } \\
\text { Ratio (OR) }\end{array}$ & $\begin{array}{l}\text { Adjusted }{ }^{a} \text { Odds } \\
\text { Ratio (OR) }\end{array}$ & $95 \% \mathrm{Cl}$ \\
\hline Patients with TTR (Rosendaal) $\geq 60 \%, n$ (\%) & $13(65)$ & $13(43.3)$ & 2.43 & 2.22 & $0.65-7.63$ \\
\hline
\end{tabular}

${ }^{a}$ Adjusted for HD vintage, total duration of hospital admission, and total duration of outpatient antibiotic use

Time in Therapeutic Range (TTR), calculated by Rosendaal method, has been used as the optimal method to assess the effectiveness and safety of warfarin anticoagulation. It was found to correlate well with bleeding and thromboembolic complications. The data on TTR in the hemodialysis population is limited to a few studies that reported TTRs ranges between 49 and 54\% $[16,18]$. These results illustrate that TTRs in hemodialysis patients trend lower than other patient populations on warfarin for atrial fibrillation $(55 \%-64.5 \%)$ [21], and supports the contention that it is more challenging to optimize warfarin treatment in hemodialysis patients.

Hemodialysis patients with atrial fibrillation have a higher risk of thromboembolic events when compared to the general population with atrial fibrillation $[7,8]$. The efficacy of warfarin in preventing thromboembolic events in hemodialysis patients with atrial fibrillation remains inconclusive [8-12, 22]. A large retrospective study by Shah et al., reported that warfarin use in dialysis patients was associated with $44 \%$ higher risk for bleeding without significant reduction of cerebrovascular events [10]. Moreover, Chan et al., described an increased risk of stroke with the use of warfarin in hemodialysis patients [11]. In contrast, a recent study by Brancaccio demonstrated a strong survival benefit with the use of warfarin in hemodialysis patients, with a $53 \%$ and $24 \%$ decreased mortality at 90 days and 6 years, respectively [9]. None of the above mentioned studies

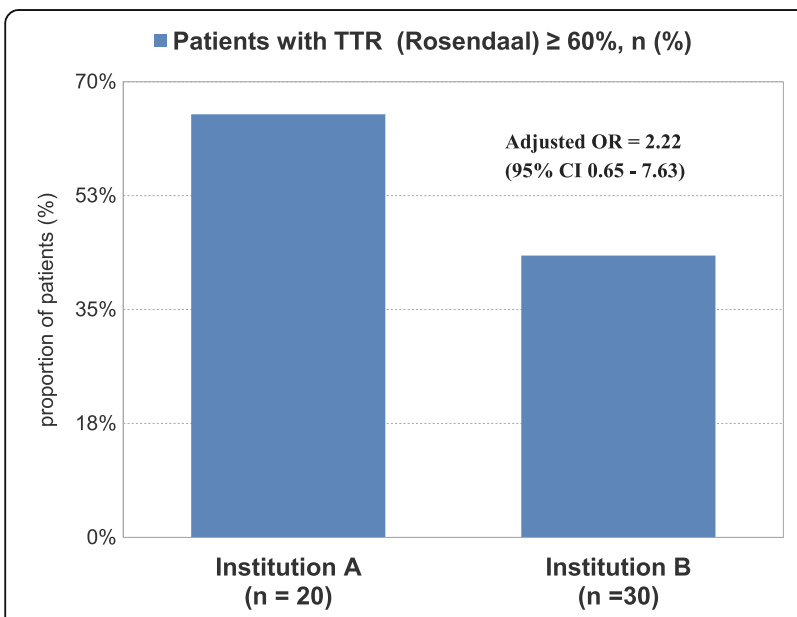

Fig. 2 Graph showing proportion of patients achieving TTR (Time in Therapeutic range) $\geq 60 \%$, based on Rosendaal method. Adjusted odds ratio (OR) of patients achieving TTR $\geq 60 \%$ in Institution $A$ is $2.22(95 \% \mathrm{Cl} 0.65-7.63)$ reported the TTR data in their study subjects. Currently, no clear explanation is forthcoming regarding the inconsistent impact of warfarin in hemodialysis patients with atrial fibrillation. This equipoise may be due, in part, to suboptimal TTRs typically achieved in this population. Therefore, it seems reasonable that efforts be directed towards improving TTR in hemodialysis patients to bring them into line with those achieved in other populations with atrial fibrillation, in whom warfarin treatment has been decidedly beneficial.

There is considerable evidence in the literature of general population with atrial fibrillation that achieved TTR can vary depending on the specialty of healthcare providers responsible for managing the warfarin therapy $[19,20]$. However, the evidence of superiority for a specific provider-led management of anticoagulation in hemodialysis population is scarce. A study by Thomson et al. involving 64 outpatient hemodialysis patients compared nephrologist-led warfarin therapy to that of a nomogram-directed therapy managed by dialysis nurses, and showed that both strategies resulted in similar proportions of INR readings within target range, with less frequent INR testing associated with the nomogramdirected therapy [17]. However, this study did not analyze INR data using the Rosendaal method, which is the superior methodological standard to assess adequacy of warfarin anticoagulation $[14,15]$. In our study, we observed that a higher proportion of patients had achieved therapeutic TTRs assessed by Rosendaal method with nephrologist-led management compared to anticoagulation clinic-led management, and that the nephrologistdirected management was associated with more frequent INR testing. The higher proportion of patients achieving target TTRs with nephrologist-led management may be due to the frequent and direct contact between nephrologists and hemodialysis patients. This dynamic facilitates timely and intimate knowledge of the patient's clinical course (bleeding events, antibiotic exposure, adherence, etc.) which is often lacking in the case of the anticoagulation clinic-led management. The higher frequency of INR testing observed with the nephrologist-led management may be a consequence of this relationship or an independent contributor to improved results.

Our study has some noteworthy limitations. Firstly, the relatively small patient sample size and the inclusion of only two university-afflicted dialysis centers limits both the statistical power of the outcome measures and the broader inference to all hemodialysis patients. Secondly, 
the observational nature of this study may introduce the possibility of unmeasured bias. However, we did obtain data on many key factors that could influence TTR values in patients on warfarin, such as HD vintage, outpatient antibiotic use, and total duration of hospital admissions, and we adjusted for them in our TTR analysis.

Our study can be considered as a hypothesis- generating for a subsequent, larger, prospective study addressing whether improved TTRs can be widely achieved in hemodialysis patients, possibly through nephrologistdirected management of warfarin dosing, and whether improved therapy will translate into stroke reductions and less bleeding complications as seen in other patient populations with atrial fibrillation.

\section{Conclusion}

There was no statistical difference of mean TTR between nephrologist-led management of warfarin to that of anticoagulation clinic-led management. However, the former achieved a trend of higher proportion of patients with optimal TTR which was associated with more frequent monitoring and greater cost effectiveness.

\section{Abbreviations}

INR: International normalized ratio; JGH: Jewish General Hospital; MUHC: McGill University Health Centre; OR: Odds ratio; SD: Standard deviation; TTR: Time in therapeutic range

\section{Availability of data and materials}

Available by request from corresponding author.

\section{Authors' contributions}

HB (Concept/design; data analysis/interpretation; drafting article; approval of article), AA (Concept/design; data analysis/interpretation; drafting article; approval of article), AD (Data analysis/interpretation; drafting article; approval of article), MLL (Concept/design; critical review of article; approval of article). All authors read and approved the final manuscript.

\section{Ethics approval and consent to participate}

The study was approved by the Medical/Biomedical Research Ethics Committee of the West-Central Montreal Island Health Board. All procedures performed in studies involving human participants were in accordance with the ethical standards of the institutional and/or national research committee and with the 1964 Helsinki declaration and its later amendments or comparable ethical standards.

\section{Consent for publication}

Data was obtained from electronic medical records retrospectively after ethics committee approval. No direct patient contact including consent took place.

\section{Competing interests}

The authors declare that they have no competing interests.

\section{Publisher's Note}

Springer Nature remains neutral with regard to jurisdictional claims in published maps and institutional affiliations.

\section{Author details}

'Division of Nephrology, Department of Medicine, McGill University Health Centre, Montreal, Canada. 'Divisions of Internal Medicine and Cardiology, Department of Medicine, McGill University Health Centre, Montreal, Canada. ${ }^{3}$ Faculty of Medicine, McGill University, Montreal, Canada. ${ }^{4}$ Division of Nephrology, Department of Medicine, Jewish General Hospital, Montreal, Canada.
Received: 5 September 2017 Accepted: 21 December 2017

Published online: 08 January 2018

\section{References}

1. Stroke Prevention in Atrial Fibrillation Investigators. Stroke prevention in Atrial fibrillation Study.Final results. Circulation. 1991;84(2):527-39.

2. Camm AJ, Kirchhof P, Lip GY, Schotten U, et al. Guidelines for the Management of Atrial Fibrillation: the task force for the management of Atrial fibrillation of the European Society of Cardiology (ESC). Eur Heart J. 2010;31(19):2369-429.

3. January CT, Wann LS, Alpert JS, Calkins H, Cigarroa JE, Cleveland JC, et al. 2014 AHA/ACC/HRS guideline for the Management of Patients with Atrial Fibrillation: a report of the American College of Cardiology/American Heart Association task force on practice guidelines and the Heart Rhythm Society. J Am Coll Cardiol. 2014;64(21):e1-76.

4. Verma A, Cairns JC, Mitchell LB, Macle L, Stiell IG, Gladstone D, et al. 2014 focused update of the Canadian cardiovascular society guidelines for the management of atrial fibrillation. Can J Cardiol. 2014;30(10):1114-30.

5. Stroke Prevention in Atrial Fibrillation Investigators. Adjusted-dose warfarin versus low-intensity, fixed-dose warfarin plus aspirin for high-risk patients with atrial fibrillation: stroke prevention in Atrial fibrillation III randomised clinical trial. Lancet. 1996;348(9028):633-8.

6. Kearon C, Ginsberg JS, Kovacs MJ, Anderson DR, Wells P, Julian JA, et al. Comparison of low-intensity warfarin therapy with conventional-intensity warfarin therapy for long-term prevention of recurrent venous thromboembolism. N Engl J Med. 2003;349(7):631-9.

7. Bonde AN, Lip GY, Kamper AL, Hansen PR, Lamberts M, Hommel K, et al. Net clinical benefit of antithrombotic therapy in patients with atrial fibrillation and chronic kidney disease: a nationwide observational cohort study. J Am Coll Cardiol. 2014;64(23):2471-82.

8. Olesen J, Lip G, Kamper AL, et al. Stroke and bleeding in atrial fibrillation with chronic kidney disease. N Engl J Med. 2012;367:625-35.

9. Brancaccio D, Neri L, Bellocchio F, Barbieri C, Amato C, Mari F, et al. Patients' characteristics affect the survival benefit of Warfarin treatment for Hemodialysis patients with Atrial fibrillation. A historical cohort study. Am J Nephrol. 2016:44:258-67.

10. Shah M, Avgil TM, Jackevicius CA, et al. Warfarin use and the risk for stroke and bleeding in patients with atrial fibrillation undergoing dialysis. Circulation. 2014:129:1196-203.

11. Chan KE, Lazarus JM, Thadhani R, Hakim RM. Warfarin use associates with increased risk for stroke in hemodialysis patients with atrial fibrillation. J Am Soc Nephrol. 2009;20:2223-33.

12. Wizemann $V$, Tong $L$, Satayathum $S$, et al. Atrial fibrillation in hemodialysis patients: clinical features and associations with anticoagulant therapy. Kidney Int. 2010;77(12):1098-106

13. Herzog CA, Asinger RF, Berger AF, et al. Cardiovascular disease in chronic kidney disease. A clinical update from kidney disease: improving global outcomes (KDIGO). Kidney Int. 2011;80:572-86.

14. Rosendaal FR, Cannegieter SC, Van der Meer FJ, Briet E. A method to determine the optimal intensity of oral anticoagulant therapy. Thromb Haemost. 1993;69(3):236-9.

15. White HD, Gruber M, Feyzi J, Kaatz S, Tse HF, Husted S, et al. Comparison of outcomes among patients randomized to Warfarin therapy according to anticoagulant control: results from SPORTIF III and V. Arch Intern Med. 2007;167(3):239-45.

16. Quinn $L M$, Richardson $R$, et al. Evaluating time in therapeutic range for hemodialysis patients taking warfarin. Clin Nephrol. 2015;83(2):80-5.

17. Thompson BK, MacRae JF, Barnueh LF, et al. Evaluation of an electronic warfarin nomogram for anticoagulation of hemodialysis patients. BMC Nephrol. 2011;12:46.

18. Genovesi S, Rossi E, Galleni M, et al. Warfarin use, mortality, bleeding and stroke in haemodialysis patients with atrial fibrillation. Nephrol Dial Transplant. 2015:30:491-8.

19. Chiquette E, Amato MF, Bussey HI. Comparison of an anticoagulation clinic with usual medical care: anticoagulation control, patient outcomes, and health care costs. Arch Intern Med. 1998;158:1641-7.

20. Entezari-Maleki T, Dousti S, Hamishehkar H, Gholami K. A systematic review on comparing 2 common models for management of warfarin therapy; pharmacist-led service versus usual medical care. J Clin Pharmacol. 2016;56(1):24-38. 
21. Amin A, Deitelzweig SF, Jing YF, et al. Estimation of the impact of warfarin's time-in-therapeutic range on stroke and major bleeding rates and its influence on the medical cost avoidance associated with novel oral anticoagulant use-learnings from ARISTOTLE, ROCKET-AF, and RE-LY trials. J Thromb Thrombolysis. 2014;38(2):150-9.

22. Soliman EZ, Prunes RF, Go AF, et al. Chronic kidney disease and prevalent atrial fibrillation: the chronic renal insufficiency cohort. Am Heart J. 2010;159:1102-7.

Submit your next manuscript to BioMed Central and we will help you at every step:

- We accept pre-submission inquiries

- Our selector tool helps you to find the most relevant journal

- We provide round the clock customer support

- Convenient online submission

- Thorough peer review

- Inclusion in PubMed and all major indexing services

- Maximum visibility for your research

Submit your manuscript at www.biomedcentral.com/submit 